\title{
Pre Scaling Up Of Chickpea Technologies at Dawa Chefa District
}

\author{
Negussie Siyum Muluneh*, Dessalegn G, Jemal A, Berhan T, Tewabe M and Awol M \\ Sirinka Agricultural Research Center, Student of Bahir Dar University, Ethio ${ }^{\text {pia }}$ \\ *Corresponding author: Negussie Siyum Muluneh, Sirinka Agricultural Research Center, Student of Bahir Dar University, Woldiya, Ethiopia
}

Submission: April 11, 2018; Published: May 14, 2018

\begin{abstract}
Chickpea is the most important leguminous food grain in the diets of people in South and West Asia and Northern Africa [1]. In the long-term, Ethiopia's competitiveness in chickpea exports would critically depend on improving productivity, enhancing grain quality and ability to consistently supply required volumes of market-preferred products at competitive prices. Evidence from participatory variety selection showed that chick pea varieties Minjar and Kasech had a greater yield potential as compared to their categories i.e. Dessi and Kabuli types [2]. A total of 17 voluntary farmers having 5.25 ha of land were selected at Tuche kebele of Dawa chefa district. 5Qt seed of Minjar variety was provided to selected farmers based on their clustered farms. Farmers were implementing farm activities on selected experiment sites of each cluster in collaboration with extension agents. Field day has been organized by Sirinka agricultural research center and coordinating role was given for socioeconomics and agricultural extension research directorate. Farmer's during interviews reveals that using the improved variety Minjar is very important for preventing chocolate spot. Therefore, Scaling out Minjar variety should be carried at Dawa chefa and similar agro ecological areas through strengthening seed producer Cooperatives.
\end{abstract}

Keywords: Chick pea; Clustering; Field day, Minjar , Pre-scaling up

\section{Introduction}

According to Duke botanical and archeological evidence show that chickpeas were first domesticated in the Middle East and was widely cultivated in India, Mediterranean area, the Middle East and Ethiopia since antiquity. Chickpea is a high-value pulse crop that is adapted to deep black soils in the cool semi-arid areas of the tropics, sub-tropics as well as the temperate areas. Chickpea is the most important leguminous food grain in the diets of people in South and West Asia and Northern Africa. The diverse biophysical and agro-climatic conditions in Ethiopia make it very suitable for growing a number of pulses and legume crops. The crop is highly integrated into the farming system and ecologically friendly for growing in many areas that suffer from soil nutrient depletion. Chickpea is one of the important pulses traded globally. The top nine chickpea exporting countries in 2007 were India, Australia, Mexico, Canada, Myanmar, Ethiopia, USA, Tanzania and Kazakhstan. Chickpea marketing system in Ethiopia is highly under developed and poorly organized. Out of the total chickpea produced only $24 \%$ supplied for both domestic and export market [3]. This implies that the nature of production is subsistence. The export market outlet is relatively new and highly variable depending on production conditions in the major importing countries in South Asia and competitiveness with other major exporters.
In the long-term, Ethiopia's competitiveness in chickpea exports would critically depend on improving productivity, enhancing grain quality and ability to consistently supply required volumes of market-preferred products at competitive prices. Evidence from participatory variety selection showed that chick pea varieties Minjar and Kasech had a greater yield potential as compared to their categories i.e. Dessi and Kabuli types [2].

Based on this pre-scaling up of Chickpea technologies has been carried out at Dawa-chefa district at Tuche kebele having an intension of promoting and creating wider demand of the technology in the farming community.

\section{Objectives}

1. To enhance technology dissemination and multiplication

2. To create a wider demand on chick pea technology

3. To create and strengthen linkage among stakeholders

\section{Materials and Methods}

A total of 17 voluntary farmers having 5.25 ha of land were selected at Tuche kebele of Dawa chefa district. Training was provided for extension agents and district experts on seed 
production, handling and technology package in general. 5Qt seed of Minjar variety was provided to selected farmers based on their clustered farms. Farmers were implementing farm activities on selected experiment sites of each cluster in collaboration with extension agents.

Agronomic practices such as row planting, appropriate seed rate, weeding and others have been applied by the clustered farmers. Site selection has been made by the researchers of SARC in collaboration with woreda agricultural experts and kebele agricultural extensionists but in the clustering of farmers the respective kebele and woreda agricultural officers as well as kebele leaders have highly participated.

\section{Method of data collection}

Necessary data were collected via informal discussion, DAs and farmers, field observation on farmers' fields.

\section{Approach used for technology pre-scaling up}

There are different approaches currently used for disseminating different agricultural technologies both in Ethiopia and abroad. The most commonly used approach in our circumstance is clustering approach. Cluster as the name indicates it is a group of farmers who have shared interests in which their farms are sidelined each other.

\section{Steps followed for clustering}

1. Communicating with the district office of agriculture for the appropriate site selection

2. Verifying the selected farms by SARC team of researchers/ biological and social scientists

3. Creating common understanding for the farmers about the technology which is going to be scaled out, responsibilities to be handled and others

4. Organizing the farmers based on their farms available in that clustered farms

\section{Site selection}

Site selection was carried out by a multi-disciplinary team of researchers, district office of agriculture and kebele DAs. Especially kebele DAs have devoted their time for this task. The study areas were kebele 014 for Meket and 017 kebele which is located in Arbit/Wadla district.

\section{Stakeholder's Analysis}

It is obvious that agricultural research without multi stake holders' participation has become unsustainable. Especially agricultural extension researches can't play the role of changing the targets/ farmers without participating the beneficiaries and other stakeholders; here under it has been tried to show that who does what in accomplishing our task.

\section{Sirinka agricultural research center}

1. Identifying thematic areas

2. Prioritizing crop varieties for wider dissemination
3. Discussion with the target districts

4. Site selection

5. Giving technical as well as administrative support

6. Organizing trainings

7. Follow up

8. Serve as technology source

9. Preparing field days

\section{Zone office of agriculture}

1. Coordinate district office of agriculture and increase the linkage among stakeholders

2. Facilitate the supply of agricultural inputs timely

\section{District office of agriculture}

1. Build a better linkage $b / n$ researchers and kebele level agricultural officers

2. Avail fertilizer on time

\section{Kebele development agents}

1. Select clustered farm land which can be suitable to the technology

2. Convince farmers about the merits of the technology

3. Provide technical support on preparation of farm land, planting, weeding, harvesting and threshing

4. collecting Data

5. Organize farmers field day in collaboration with Subject matter Specialists and Sirinka Agricultural Research Center

6. Monitoring and evaluation

\section{Farmers}

1. Willingness to provide their farmland, information, labor and time for implementing research activities

2. Active participation on problem identification, planning and implementation, monitoring and evaluation of activities

\section{Results and Discussion}

Farmers have taken an agreement with woreda office of agriculture to pay back the seed in kind at the end of the production season. For this $\mathrm{MoU}$ has been reached $\mathrm{b} / \mathrm{n}$ farmers and kebele DAs. Based on that agreement initial seeds from farmers had been collected and revolved for other farmers due to higher demand for the technology. In the study area farmers are familiar with producing vegetables using the irrigation water therefore chickpea seed production can be effective at irrigation season for the main cropping season. Since, seed producer FREG (farmers-researcher and extension group) has been established at the irrigation scheme, the process would be easy tostart. An exchange of seed with other farmers/ at least for five neighboring farmers/ had been one of 
the job done by the participant farmers for increasing technology dissemination and promotion.

\section{Field day}

It is an inevitable that field day has a paramount role for enabling stakeholders for creating awareness about technology characteristics and feasibility. It plays a great role for technology promotion. Field day has been organized by Sirinka agricultural research center and coordinating role was given for socioeconomics and agricultural extension research directorate. In this field day there was great participation of Medias from different organizations.

Field day participants were

1. Administrative bodies of zonal ,district and kebele level

2. Agricultural experts from three administrative zones/ north wollo, south wollo and oromiya zones

3. North and South wollo Zone Office of government communication affairs

4. Ethiopian broadcasting corporation /EBC/ Dessie branch

5. Amhara mass media

6. Amhara region agricultural institute/ARARI/ public relatio

\section{Farmers and field day participants' feedback}

1. Farmers during interviews reveals that using the improved variety Minjar is very important for preventing chocolate spot

2. In the study area farmers haven't been familiar with producing Kabuli type chickpea

3. Farmers had been impressed by the productivity of this variety

4. Participant farmers considered themselves as lucky for getting the technology by SARC

\section{Lessons learnt}

1. Full participation of stakeholders plays an invaluable role to be successful in every technology pre-scaling
2. Pre scaling up needs great coordination among stakeholders for its sustainability

3. Policy support is very decisive for effective and sustainable technology dissemination among the farming family

\section{Constraints}

1. Shortage of improved seed

2. Shortage of vehicles for close follow up

3. Erratic rainfall

4. Lack of awareness about the importance of agricultural technologies among farmers

\section{Conclusion}

1. Seed multiplication should be given great attention to reach a large segment of the farming community

2. Strengthening linkage among stakeholders is very essential for the success and sustainability of agricultural technology promotion and adoption

3. Trust granted training is very crucial to create awareness on technology package

4. There should be appropriate site selection for improving agricultural production and productivity

\section{The Way Forward}

1. Scaling out Minjar variety should be carried at Dawa chefa and similar agro ecological areas

2. Seed multiplication should be done on the established FREGs at Dawa chefa district.

\section{References}

1. James Duke A (1981) Hand book of legumes world economic importance, plenum press, New York, USA.

2. (2014) Participatory variety selection of chick pea at Legambo and Dawa Chefa, unpublished.

3. Central statistical authority (CSA) (2007) Agricultural sample survey, Addis Ababa, Ethiopia.

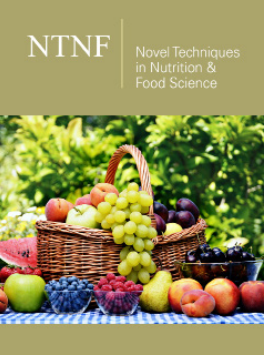

Novel Techniques in Nutrition and Food Science

\section{Benefits of Publishing with us}

- High-level peer review and editorial services

- Freely accessible online immediately upon publication

- Authors retain the copyright to their work

- Licensing it under a Creative Commons license

- Visibility through different online platforms 